\author{
E. E. Doğan \\ İstanbul University-Cerrahpaşa Faculty of Medicine Fatih/İstanbul, Turkey \\ enesemredogan7979@gmail.com
}

\title{
HYDROGEN PRODUCTION AND ITS STORAGE FROM SOLAR ENERGY
}

\begin{abstract}
The aim of this study is to increase the energy efficiency of the solar panel, to make the waste heat generated under the panel efficient and to store the electrical energy produced from solar panels in the form of hydrogen in boron nitride and boron carbide. Characterization of boron nitride and boron carbide was carried out with Fourier transform infrared spectroscopy-attenuated total reflectance (FTIR-ATR), differential thermal and thermogravimetric analysis (DTA/TG), Brunauer-Emmett-Teller (BET) and scanning electron microscopyenergy dispersive X-ray spectroscopy (SEM/EDX). The specific surface areas and pore sizes of the boron nitride and boron carbide were determined as 78 and $20 \mathrm{~m}^{2} / \mathrm{g}$; and 3.8 and $11.1 \mathrm{~nm}$, respectively. DTA/TG thermograms showed that boron nitride degraded in one step in the temperature range of $30-550^{\circ} \mathrm{C}$ and boron carbide degraded in two steps. From experimental studies, approximately $8.7 \%$ energy efficiency was achieved and hydrogen energy was costless produced from a renewable energy source excluding system costs. Moreover, it was found that $276 \%$ and $208 \%$ more hydrogen could be stored in the boron compounds, the boron nitride had more hydrogen storage capacity, and the electrical efficiency of the panel was increased.
\end{abstract}

Keywords: Solar panel; energy; hydrogen; boron compounds

\section{INTRODUCTION}

In parallel with the increasing population and urbanization in the 21 st century, the energy need of the globe has rapidly increased [1]. In line with this determination, it is stated that the energy demand will increase by 53\% from 2008 to 2035 [2]. Existing energy sources in the world are classified as fossil, nuclear and renewable energies. Today, $88 \%$ of the world's energy demand is met by fossil fuels and the remaining $12 \%$ by nuclear and renewable energy sources [1]. The steady decrease in fossil fuel reserves and their caused environmental pollution are necessary to the effective use of renewable energy sources and the exploration of alternative energy sources [3]. The most important renewable energy sources are solar energy, wind energy, geothermal energy, hydroelectric energy, bioenergy, hydrogen energy and marine energy $[3,4]$. Solar energy and hydrogen energy have recently come to the fore among renewable energy sources. Because solar energy is a renewable and non-polluting, clean 
energy source produced from direct sunlight without any harmful gas emissions. The foundation of solar energy is based on the collection of photons coming from the sun through solar panels and converting the energy carried by photons into electrical and heat energy. Hydrogen is considered as a source of energy that can replace fossil fuels due to its high heat value and no environmental pollution [3]. In general, hydrogen can be stored in different forms [5]. The possible approaches to store hydrogen are physical storage of compressed hydrogen gas in high pressure tanks (up to 700 bar), physical storage of cryogenic hydrogen (cooled to $-253^{\circ} \mathrm{C}$, at pressures of 6-350 bar in insulated tanks) and the storage in the solid matrix [6-10]. Among these methods, the cheapest and safest storage is the adsorption of hydrogen in special solids. Hydrogen can be stored in solid materials such as metal hydrides, organo-metal compounds, zeolites, carbon derivatives [1]. Since the amount of hydrogen adsorbed in these adsorbents is not yet at the desired ratio, research on adsorbents that can store high amounts of hydrogen have continued.

Some countries in the world come to the forefront with different renewable energy fields depending on their geographical location and technological developments. China is leader the world in electricity generation through wind and hydraulic energy. Germany is in the first place in electricity generation with the help of photovoltaic panels. America is the country that makes the most use of biofuels in the world. In addition, Canada, Japan and the Netherlands are other countries that make significant use of renewable energy sources. Turkey uses hydro, geothermal and solar energy systems [2]. Despite the increasing tendency to renewable energy sources all over the world, the lack of continuity of these resources and the high production and investment costs constitute an obstacle to these resources [11].

The current situation has necessitated the use of energy in the most efficient manner and accelerated the studies on energy storage methods. Although there are many methods for storing energy, storage in the form of heat energy and in the form of hydrogen is common because of its ease of application [12]. As it is known, energy does not disappear but only its quality changes. Directing the energy that has partially lost its quality in the form of waste heat to the areas that can be used and the studies carried out in this regard provide energy saving. It is possible to ensure the continuity of the resources that exist in certain time periods such as solar energy and which do not exist at other times through energy storage. Because of this necessity, heat energy storage methods are of great importance both in solar energy systems and application areas requiring waste heat recovery [13]. Despite the decrease observed in fossil fuels in recent years, the increasing energy demand, the inability to store electrical energy, and the increased environmental awareness have led to the search for alternative energy sources. This study draws attention to the efficient use of solar energy, which is one of the renewable energy sources as an alternative to both global warming and increasingly depleted fossil fuels, and to store this energy in hydrogen form.

For efficient use of energy, it is only necessary to store the waste heat or heat that is available for a certain period of time, such as solar energy, which is a renewable energy source. As stated in the above explanations, it is seen that the adsorbents used for hydrogen storage are not at the desired level in hydrogen storage, yet. Hydrogen storage in hydrocarbons is a conventional method, but it creates carbon dioxide emission. Using metal hydrides in electrochemical batteries is an old and rapidly improving method for hydrogen storage. They are capable of absorbing and desorbing hydrogen with small pressure variations. Utilization of hydrides is also a promising technique for on-board hydrogen storage. A new method is the use of nanostructural materials. It is advantageous compared to other methods for the storage of hydrogen due to some features such as boron and its compounds are generally not flammable/explosive and environmentally friendly. The most important nano-technological refined products of boron are boron nitride and boron carbide. Boron nitride is a dielectric material with a wide band gap of 5-6 eV and when crystallized in 
porous structure displays unique physical and chemical properties, including high specific surface area, low density, superb corrosion resistance, high thermal conductivity, chemical durability and oxidation resistance. These features make porous boron nitride a promising candidate for applications in various fields, such as hydrogen storage, organic and inorganic pollutant adsorption and catalysis in very harsh environments. In recent years, boron carbide has been used in nuclear power plants for radiation protection and as a fuel loading rod [14]. The second main scope of this paper is to present the possible utilization of boron for hydrogen storage. Hydrogen storage methods incorporating boron can be divided into four main parts. These are: pyrolysis, hydrolysis, metal-hydride batteries, and nano structures such as boron nitride and boron carbide [15]. In the literature, there are a few number studies related to hydrogen adsorption on boron nitride and boron carbide. For example, Wu et al (2008) investigated the hydrogen storage capacity of pillared Li-dispersed boron carbide nanotubes and found that the boron substitution in carbon nanotube greatly enhances the binding energy of $\mathrm{Li}$ atom to the nanotube [16]. Lale et al (2018) aimed at giving a comprehensive overview of the main experimental results and findings as well as of the different avenues worth being explored. A key lesson of this study was that boron nitride might turn out to be a promising material for hydrogen storage at room conditions [17]. Petrushenko and Petrushenko (2018) discussed the results of DFT and ab initio calculations of the hydrogen physisorption on graphene, hexagonal boron nitride (h-BN), and a graphene-like boron nitride-carbon heterostructure $(\mathrm{GBNCH})$, observed that $\mathrm{GBNCH}$ had advanced adsorption properties, and found that the adsorption energies for $\mathrm{GBNCH}$ were larger than those for graphene and much larger than for h-BN [18]. Therefore, the aims of this study are $i$. to increase the energy efficiency of the panel by decreasing the temperature of the panel under the sun while generating electricity energy from the sun which is a renewable energy source, ii. to make the waste heat efficient by using the heat removed from the panel in different areas such as the houses and greenhouses, and iii. to store the electrical energy produced from solar panels in refined boron nitride and boron carbide with higher storage capacity according to the present storage systems in hydrogen form.

\section{MATERIALS AND METHODS}

\section{Characterization of materials}

Boron nitride and boron carbide were characterized using FTIR-ATR, BET, DTA/TG and SEM/EDX. FTIR-ATR spectra of samples were obtained in the wavelength range of 4000 to $650 \mathrm{~cm}^{-1}$ using a PerkinElmer Spectrum 100. Thermogravimetric analysis was performed using PerkinElmer Diamond Simultaneous DTA/TG instrument with a heating rate of 10 ${ }^{\circ} \mathrm{C} / \mathrm{min}$ from 30 to $550^{\circ} \mathrm{C}$ under nitrogen atmosphere. BET surface areas and pore sizes of the samples were mesured with the Quantachrome Nova 2200e instrument. The samples were degassed at $105^{\circ} \mathrm{C}$ for 24 hours before analysis. The surface areas and pore sizes of the degassed samples were determined by using pure nitrogen gas as adsorbate in liquid nitrogen (77 K). In order to investigate the morphological properties of the samples, scanning electron microscope (SEM/EDX) was used (Zeiss EVO LS 10).

\section{Solar panel}

In the study, the experimental setup where the energy efficiency was measured and the hydrogen energy was stored was given in Figure 1. The system consists of 50 watts solar panel, copper collectors that absorb heat under the solar panel, water tank, the engine that 
circulates the water in the system, the charge regulator, the inverter, the battery, electrolysis cell, hydrogen tank and thermometer.

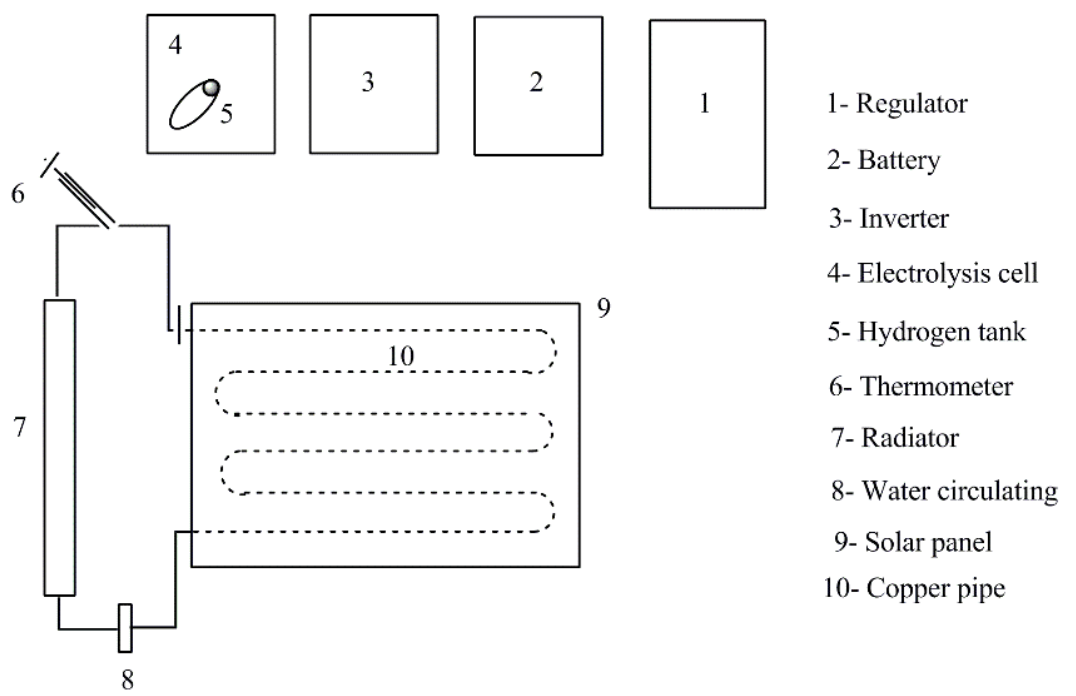

Fig. 1. Solar panel system

\section{Hydrogen storage analysis}

Hydrogen gas adsorption measurements of boron nitride and boron carbide were carried out with Hiden IMI PSI hydrogen storage device at different pressures at room and cryogenic temperatures [1].

\section{RESULTS AND DISCUSSION}

\section{Characterization of boron nitride and boron carbide}

FTIR spectroscopy provides with the crucial insight into the morphology differences of boron nitride and boron carbide. FTIR-ATR spectra of boron nitride and boron carbide were shown in Figure 2. FTIR spectra of boron nitride exhibited B-N bond at 755 and $1312 \mathrm{~cm}^{-1}$. The bands at 1312 and $755 \mathrm{~cm}^{-1}$ are related to B-N in-plane stretching mode and out of plane vibrations of h-BN, respectively. Additional band appeared at $2318 \mathrm{~cm}^{-1}$ is due to moisture absorbed on the samples during the analysis. Based on the literature on infrared studies of B$\mathrm{C}$ structures, the distinctive peaks of $\mathrm{B}-\mathrm{C}$ bonds are those at $891,1056,1233,1368,1538$, $1785 \mathrm{~cm}^{-1}[19,20]$.

BET surface areas of boron nitride and boron carbide were carried out with Quantochrome Nove2200e device by degassing at $105^{\circ} \mathrm{C}$ for 24 hours. BET surface areas and pore sizes of boron nitride and boron carbide were determined as 78 and $20 \mathrm{~m}^{2} / \mathrm{g}$; and 3.8 and $11.1 \mathrm{~nm}$, respectively.

DTA/TG thermograms of boron nitride and boron carbide in the temperature range of 30$550^{\circ} \mathrm{C}$ were given in Figure 3. While boron nitride degrades in one step, boron carbide degrades in two steps. A mass loss of about $0.66 \mathrm{wt} \%$ occurs at the decomposition step of boron nitride at $213{ }^{\circ} \mathrm{C}$. While a mass loss of $2.54 \mathrm{wt} \%$ occurs in first degradation step at $82^{\circ} \mathrm{C}$ of boron carbide, a mass loss of about $1.40 \mathrm{wt} \%$ occurs in the second degradation step at $347^{\circ} \mathrm{C}$. While the total mass loss of boron nitride in the temperature range studied is 0.66 
$\mathrm{wt} \%$, the total mass loss of boron carbide is $4.2 \mathrm{wt} \%$. These results show that boron nitride is more thermally stable.
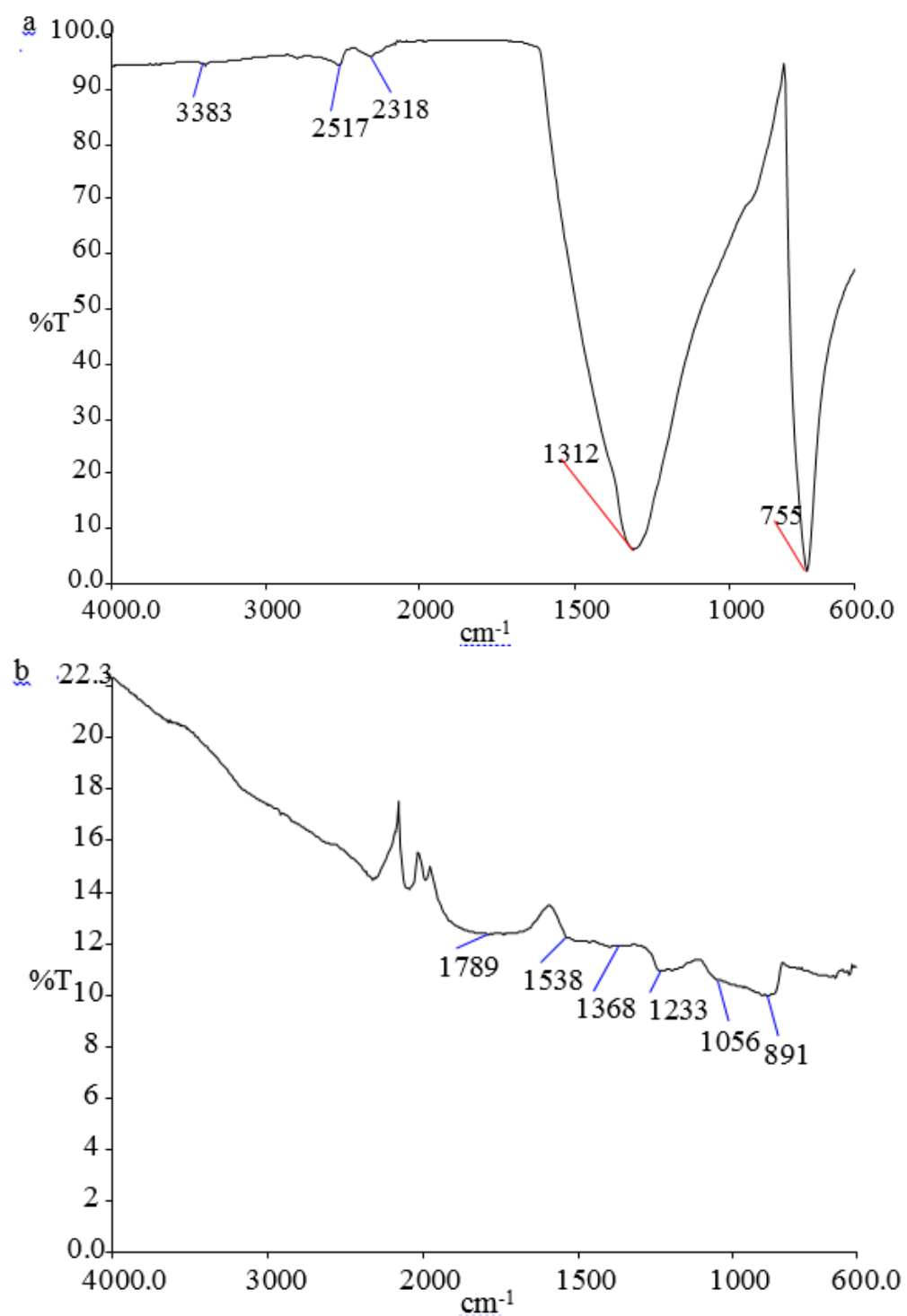

Fig. 2. FTIR-ATR spectra of a. boron nitride and b. boron carbide

The surface morphologies of boron nitride and boron carbide were carefully evaluated. The images collected by scanning electron microscope (SEM) were presented in Figure 4. It can be said from the SEM images of boron nitride that it has a rough and more fluffylike topography. Moreover, it is seen that boron nitride is agglomerated and in bulk. Energy dispersive X-ray spectroscopy (EDX) makes quantitative characterization of the sample for all elements except for those with lower atomic numbers which includes boron as well as nitrogen [20,21]. EDX analysis often provide important information about the percentage of materials, their distribution, shape and morphology. In experimental studies, EDX analysis were done on images taken by scanning electron microscopy. EDX spectra of boron nitride and boron carbide were given in Figure 4. B/C ratio in boron carbide was determined as $36.86 / 63.14$ and $\mathrm{B} / \mathrm{N}$ ratio in boron nitride as 52.04/47.96. From these results, it can be said that the boron content of boron nitride is higher than the boron content of boron carbide. 


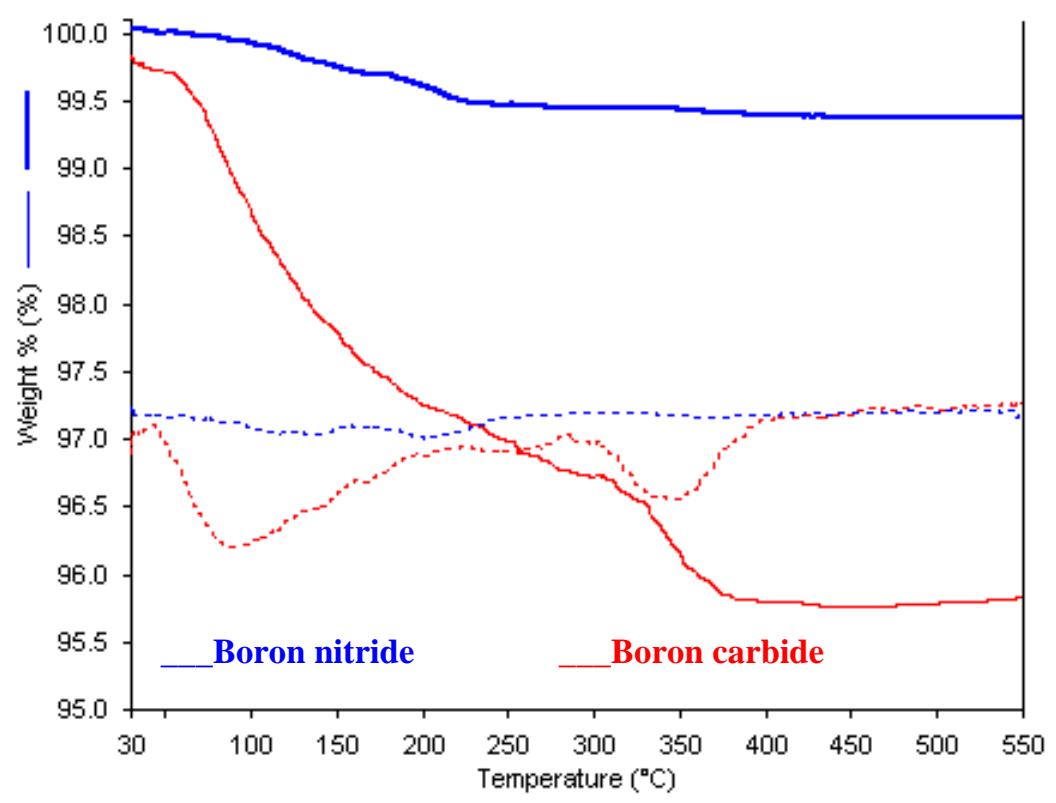

Fig. 3. TG and $d[T G]$ thermograms of boron nitride and boron carbide
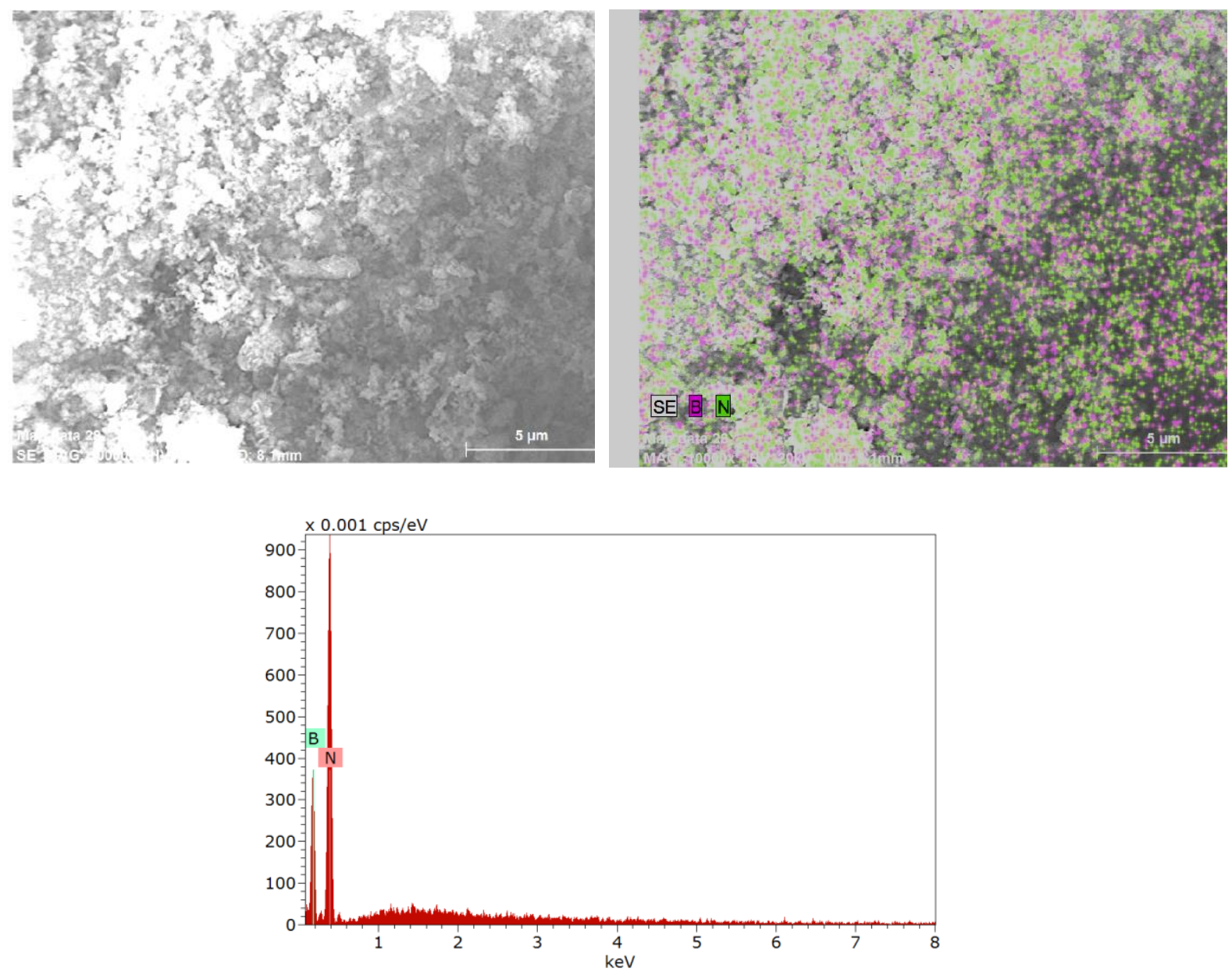

Fig. 4a. SEM/EDX images of boron nitride 

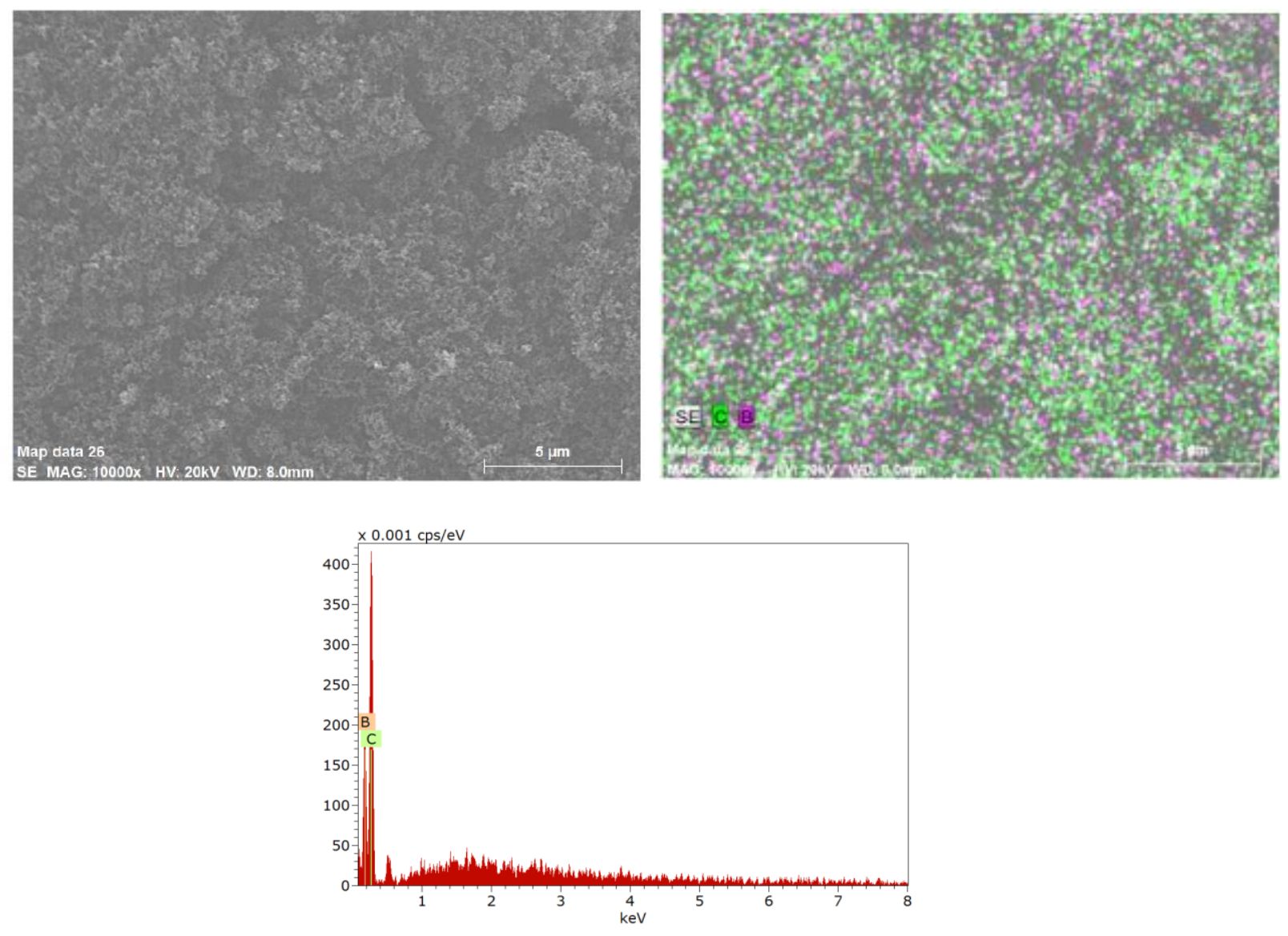

Fig. 4b. SEM/EDX images of boron carbide

\section{Solar panel - electricity generation}

There are two relationships between the sun and the terrestrial globe. These are i. the movement in the east-west direction during the day; and ii. the angular change between the sun and the earth depending on the season. In the literature, an optimum angle of $32^{\circ}$ was found to be suitable for solar panels in Balikesir in Turkey [22]. Electricity production in the solar panel begins with the emission of light from the sun. However, the electricity produced in the solar panel decreases due to the increase in panel temperature. Therefore, it was aimed to increase the efficiency by decreasing the temperature of the solar panel in the experimental setup. In the experiment, the short-circuit current of the solar panel was initially measured as 2.71 Amps at $21^{\circ} \mathrm{C}$. Then, the panel was kept under the sun for 1 hour and the short-circuit current of the heated panel decreased to 2.64 Ampere.

There are three basic parameters for photovoltaic panel: panel power $(\mathrm{P})$, panel open circuit voltage (V), and panel short circuit current (I). In short, the power of the panel is directly proportional to the voltage and current $(\mathrm{P}=\mathrm{VxI})$. In the experimental study, the current decreased with increasing temperature. Increasing of the temperature at constant voltage (voltage) caused the current to decrease, thus, decreasing the power of the panel. This is not desirable situation for energy efficiency. This decrease can mathematically write as follows:

Initial power of the solar panel at constant voltage: $\quad(\mathrm{P})=\mathrm{V} \times 2.71$

Power of the solar panel at constant voltage after 1 hour: $\quad(\mathrm{P})=\mathrm{V} \times 2.64$

Decreasing in the power of the panel $=100-(\mathrm{V} \times 2.64) /(\mathrm{V} \times 2.71) \times 100=2.5 \%$ 
In order to eliminate this negative effect, both the temperature of the panel and the heat removed from the panel should be stored for use in different areas. By lowering the temperature of the panel, it can be said that the energy efficiency of the panel can be increased by at least $2.5 \%$.

\section{Solar panel - hot water production}

In order to make the heat generated in the solar panel efficient, a collector made of copper pipe was placed on the back side of the panel, and then, it was insulated with insulation material and transparent plate. The aim is to increase the electrical efficiency by lowering the temperature of the solar panel and also, to take advantage of the liquid temperature circulated in the collector. Thus, energy efficiency would be ensured by evaluating the waste heat. In the experimental study, the initial temperature of the collector water was measured as $21^{\circ} \mathrm{C}$. The panel was placed under the sun at around 13.00 hours (pm) and the circulation pump in the experimental setup was operated with the electricity produced from the panel. After one hour, the temperature of the collector water was measured as $50^{\circ} \mathrm{C}$ by thermometer.

In order to heat a $100 \mathrm{~m}^{2}$ house, it is necessary to use one radiator per $10 \mathrm{~m}^{2}$. The amount of heat per hour each radiator emits is about $1800 \mathrm{kcal}$. In the experimental study, the initial temperature of the water in the radiator was measured as $21{ }^{0} \mathrm{C}$. After one hour, the temperature of the water in the radiator rose to $50^{\circ} \mathrm{C}$. In this case, the amount of heat drawn from the solar panel;

$$
\begin{aligned}
& \mathrm{q}=\mathrm{mC} \Delta \mathrm{T} \\
& \mathrm{q}=1500 \mathrm{~g} \times 1 \mathrm{cal} / \mathrm{g}^{\circ} \mathrm{C} \times 29^{\circ} \mathrm{C}=43.5 \mathrm{kcal}
\end{aligned}
$$

In this study, 50 Watt solar panel was used. In domestic solar panels, 300 Watt panels are generally used. In order to meet the energy requirements of a $100 \mathrm{~m}^{2}$ house, 5 and/or 6 panels are required. In this case, the amount of energy to be obtained from these panels:

$$
\mathrm{q}=43.5 \times 6 \times 6=1566 \mathrm{kcal}
$$

As it is seen from the above results, $1800 \times 10=18.000 \mathrm{kcal}$ per hour is needed to heat a house. In this case;

$$
\% \text { energy efficiency }=(1566 / 18000) \times 100=8.7 \% \text {. }
$$

This result indicates that $8.7 \%$ energy gain will be achieved by evaluating the heat generated under the panel.

\section{Hydrogen adsorption isotherm}

The results of the hydrogen storage capacity of boron nitride and boron carbide at different pressures at room and cryogenic temperatures were plotted in Figure 5a and b. As can be seen from the figure, the boron nitride has a higher hydrogen storage capacity than the boron carbide. 
a)

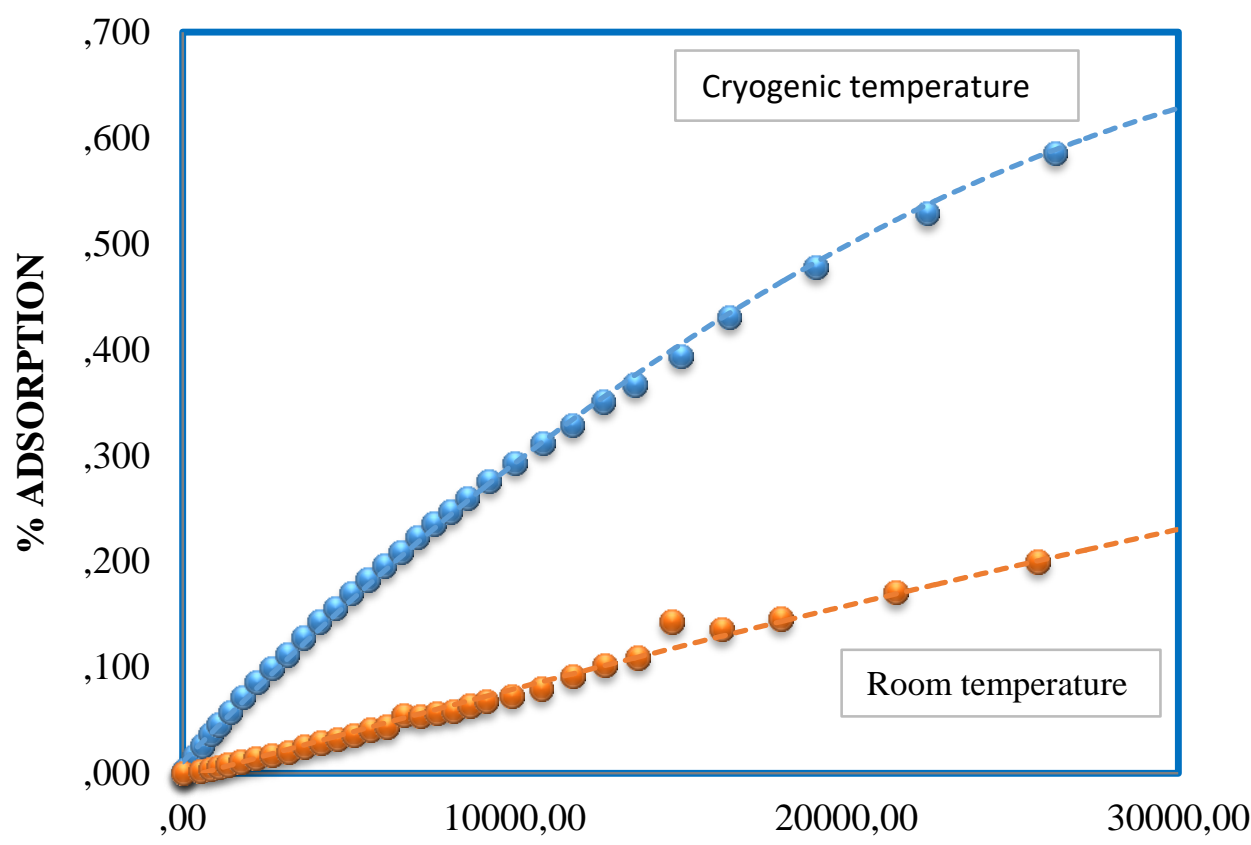

PRESSURE (MBAR)

b)

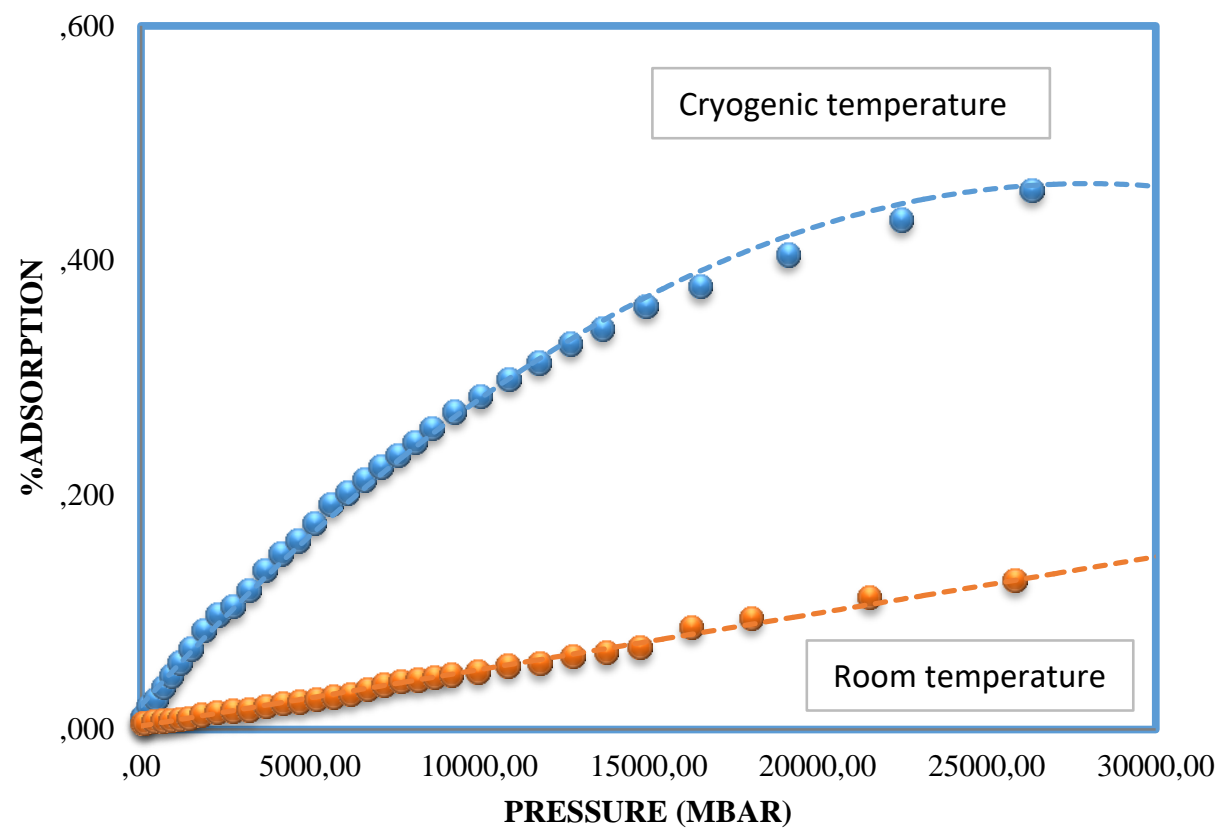

Fig. 5. Hydrogen adsorption amounts of boron compounds at different pressures and temperatures: a) boron nitride and b) boron carbide

In general, in gas stations, hydrogens are stored in high-pressure (usually 150 bar) 50 liter tubes. The volume of high purity hydrogen stored in these tubes is $6.6 \mathrm{~m}^{3}$. In this study, hydrogen was stored in tubes of $100 \mathrm{~mL}$ volume containing boron nitride and boron carbide. The volume of hydrogen in $30 \mathrm{~L}$ tubes is $1.32 \mathrm{~m}^{3}$. As shown in Figure $5 \mathrm{a}$ and $\mathrm{b}$, the amounts of hydrogen adsorbed at cryogenic temperature at 30 bar in boron nitride and boron carbide are 0.65 and $0.49 \mathrm{gr}$, respectively. When these amounts are converted to volume units; 


$$
\begin{aligned}
& \mathrm{V}=\frac{\mathrm{m}}{\mathrm{d}}=\frac{0.65}{0.0889}=7.3 \mathrm{~L}(\text { Boron nitride }) \\
& \mathrm{V}=\frac{\mathrm{m}}{\mathrm{d}}=\frac{0.49}{0.0889}=5.5 \mathrm{~L}(\text { Boron carbide })
\end{aligned}
$$

The tubes used in the study have a volume of $0.1 \mathrm{~L}$. Considering $50 \mathrm{~L}$ tubes, the above volumes should be multiplied by 500 . In this case;

$$
\begin{aligned}
& \mathrm{V}_{\text {boron nitride }}=500 \times 7.3=3650 \mathrm{~L}=3.65 \mathrm{~m}^{3} \\
& \mathrm{~V}_{\text {boron carbide }}=500 \times 5.5=2750 \mathrm{~L}=2.75 \mathrm{~m}^{3}
\end{aligned}
$$

The above results show that if boron nitride and boron carbide produced from boron minerals use in hydrogen storage, $276 \%$ and $208 \%$ hydrogen can be stored more in the same volume, respectively. In this study, hydrogen was produced from the electrolysis of water by using electricity produced from solar panels and stored in tubes in nano technological boron compounds. Since the structure of the boron compounds used in the study does not break up and hydrogen is physically adsorbed, these compounds can be used in hydrogen storage repeatedly. Once the hydrogen generation system from solar panels has been installed and maintained, it can be used for many years. The above results show that hydrogen can be produced free of charge from a renewable energy source (excluding system cost) and that if the nano technological boron nitride and boron carbide compounds use for the storage of hydrogen, 276 and 208\% more hydrogen can be stored in the same volume, respectively.

\section{CONCLUSIONS}

Boron nitride and boron carbide was characterized by FTIR-ATR, DTA/TG, BET and SEM/EDX. The specific surface areas and pore sizes of the boron nitride and boron carbide was determined as 78 and $20 \mathrm{~m}^{2} / \mathrm{g}$; and 3.8 and $11.1 \mathrm{~nm}$, respectively. DTA/TG thermograms showed that boron nitride degraded in one step in the temperature range of $30-550^{\circ} \mathrm{C}$ and boron carbide degraded in two steps. Approximately $8.7 \%$ energy efficiency was achieved by using the heat generated under the solar panel. Hydrogen was produced costless from a renewable energy sources excluding system costs. It was found that 276 and $208 \%$ more hydrogen could be stored in boron nitride and boron carbide compounds in tubes of the same volume, respectively and determined that more hydrogen would be stored in boron nitride due to its tube structure. In addition, continuous heat was removed from the panel, the panel's heating was prevented and energy efficiency of the panel was increased by at least $2.5 \%$.

\section{REFERENCES}

1. Doğan, E.E., Tokcan, P., Kızılduman, B.K. Storage of hydrogen in activated carbons and carbon nanotubes. Advances in Materials Science, 18(4), (2018) 5-16.

2. Ökten, K., Özdemir, M. 2016. Thermal investigation of tanks equipped with glasswool to maintain temperature differences in heat recovery and storage. Sakarya University Journal of Science, 20(2) (2018) 291-299. 
3. Mormillan, M., Veziroglu, T.N. Current status of hydrogen energy. Renewable and Sustainable Energy Reviews, 6(1-2), (2002) 141-179.

4. Karabacak, K., Çetin, N. Artificial neural networks for controlling wind-PV power systems: A review. Renewable and Sustainable Energy Reviews, 29, (2014) 804-827.

5. Yang, J., Sudik, A., Wolverton, C., Siegel, D.J. High capacity hydrogen storage materials: attributes for automotive applications and techniques for materials discovery. Chemical Society Reviews, 39, (2010) 656-675.

6. Chattaraj, P.K., Bandaru, S., Mondal, S. Hydrogen storage in clathrate hydrates. Journal of Physical Chemistry A, 115, (2011) 187-193.

7. Das, R., Chattaraj, P.K. A (T-P) phase diagram of hydrogen storage on $\left(\mathrm{N}_{4} \mathrm{C}_{3} \mathrm{H}\right)_{6} \mathrm{Li}_{6}$. Journal of Physical Chemistry A. 116, (2012) 3259-3266.

8. Gutowska, A., Li, L. Shin, Y., Wang, C.M., Li, X.S., Linehan, J.C., Smith, R.S., Kay, B.D., Shaw, B.S.W., Gutowski, M., Autrey, T. Nano scaffold mediates hydrogen release and there activity of ammonia borane. Angewandte Chemie International Edition, 44, (2005) 3578-3582.

9. Nouar, F., Eckert, J., Eubank, J.F., Forster, P., Eddaoudi, M. Zeolite-like metalorganic frameworks (ZMOFs) as hydrogen storage platform: lithium and magnesiumion-exchange and H2-(rho-ZMOF) interaction studies. Journal of the American Chemical Society, 131, (2009) 2864-2870.

10. Stergiannakos, T., Tylianakis, E., Klontzas, E., Froudakis, G.E. Enhancement of hydrogen adsorption in metal-organic frameworks by $\mathrm{Mg}^{+2}$ functionalization: a multiscale computational study. Journal of Physical Chemistry C. 114, (2010) 16855-16858.

11. Paksoy, H., Evliya, H., Turgut, B., Mazman, M., Konuklu, Y., Gök, Ö., Y1lmaz, M.Ö., Y1lmaz, S., Beyhan, B., Şahan, N. Evaluation of alternative energy sources with thermal energy. 11th Energy Congress, İzmir-Türkiye, 2009.

12. Kozak, M., Kozak, Ş. Energy storage methods. Suleyman Demirel University International Journal of Technological Science, 4(2), (2012) 17-29.

13. Dinçer, I., Rosen, M.A. Thermal energy storage systems and applications. NewYork, 2002.

14. Li, J., Lin, J., Xu, X., Zhang, X., Xue, Y., Mi, J., Mo, Z., Fan, Y., Hu, L., Yang, X., Zhang, J., Meng, F., Yuan, S., Tang, C. Porous boron nitride with a high surface area: hydrogen storage and water treatment. Nanotechnology. 24, (2013) 155603 (7pp).

15. Fakiroğlu, E., Yürüm, Y., Veziroğlu, T.N. A review of hydrogen storage systems based on boron and its compounds. International Journal of Hydrogen Energy. 29, (2004) 1371-1376.

16. Wu, X.J., Gao, Y., Zeng, X.C. Hydrogen storage in pillared Li-dispersed boron carbide nanotubes. Journal of Physical Chemistry C. 112(22), (2008) 8458-8463.

17. Lale, B., Bernard, S., Demirci, U.B. Boron nitride for hydrogen storage. ChemPlusChem. 83, (2018) $893-903$.

18. Petrushenko, I.K., Petrushenko, K.B. Hydrogen adsorption on graphene, hexagonal boron nitride, and graphene-like boron nitride-carbon heterostructures: A comparative theoretical study. International Journal of Hydrogen Energy. 43, (2018) 801-808.

19. Sattanathan, M., Subramani, S., Mohamed, K., Devarajan, M., Nasir, R.M. Synthesis and characterization of hexagonal boron nitride coating on polyethylene terephthalate. Iranian Polymer Journal. 28, (2019) 969-976.

20. Pillari, L.K., Umasankar, V., Elamathi, P., Chandrasekar, G. Synthesis and characterization of nano hexagonal boron nitride powder and evaluating the influence on aluminium alloy matrix. Materials Today Proceedings. 3, (2016) 2018-2026. 
21. Al Meslmani, B., Mahmoud, G., Strehlow, B., Mohr, E., Leichtweiß, T., Bakowsky, U. Development of thrombus-resistant and cell compatible crimped polyethylene terephthalate cardiovascular grafts using surface co-immobilized heparin and collagen. Materials Science and Engineering: C, 43, (2014) 538-546.

22. Rustemli, S., Dinçadam, F., Demirtaş, M. Hot water production with solar cells and street lighting. V. Renewable Energy Resources Symposium, 42-29 Diyarbakır-Türkiye, 2009. 